\title{
Las otras protagonistas de la rondallística catalana: modelos para adaptar y enseñar
}

\section{The other protagonists of Catalan rondallística: some models for adaptation and teaching}

\author{
ALÍCIA SANTOLÀria ÒrRIOS \\ Grupo GIEL ${ }^{1}$ \\ Facultat de Magisteri (Universitat de València) \\ alicia.santolaria@uv.es
}

\begin{abstract}
Resumen: El artículo reivindica la literatura tradicional para la escuela. Se pone la mirada especialmente en los personajes femeninos de dicha literatura. Asimismo se comparan personajes muy conocidos como Cenicienta, la Bella durmiente o Blancanieves con otros rescatados de la rondallística catalana que presentan otros rasgos más activos y resolutivos como la Dent d'or, Blancaflor o Rosella. La investigación propone la escritura de textos en situación de aula, en los primeros niveles escolares, a partir de la revisión del canon escolar y la lectura de cuentos.
\end{abstract}

Palabras clave: rondallística, personajes femeninos, canon escolar, lectura de clásicos, escritura inicial.

\begin{abstract}
This article claims the traditional literature for school. It especially focuses on the female characters of this type of literature. In the same manner, characters which are familiar to us such as Cinderella, Sleeping Beauty or Snow White are compared with other rescued characters from the Catalan folktales, which have other more decisive and active features as for example Dent d'or, Blancaflor or Rosella. This research suggests writing texts in the classroom in the early year levels, taking as a starting point the review of the school norms and the storytelling.
\end{abstract}

Keywords: Catalan folktales, female characters, school norms, reading the classics, initial writing.

${ }^{1}$ El Grup d'Investigació en Ensenyament de Llengües (código GIUV2013-081) está constituido por diferentes profesoras y profesores de las didácticas de las tres lenguas del currículo valenciano (catalán, castellano e inglés). Se ocupa, además, de investigar en todos los niveles educativos desde la Educación Infantil hasta el grado de Magisterio. 
Dentro del marco que se nos sugiere, se nos propone ahondar en las Literaturas hispánicas en el contexto europeo; de lo que se tratará en este artículo, dado que es un título muy amplio, es de la rondallística y, por lo tanto, de literatura tradicional ${ }^{2}$. Dentro de este campo, también observaremos los personajes femeninos de dicha literatura en relación con la escuela. Veremos lo que se lee en este espacio y cuáles son las heroínas que se presentan. Aportaremos otras, ancladas en nuestra tradición cultural que exhiben otras características, más activas y resolutivas. Nos adentraremos en uno de los mayores retos de la literatura tradicional: las adaptaciones de los clásicos y, finalmente, ofreceremos algún ejemplo de lo que han escrito los niños pequeños a partir de estos cuentos antiguos (pero nuevos para casi todos) dentro de un proyecto en el que se involucra la escuela.

Lo primero que hay que señalar es que se ha optado por el término rondallística aunque no existe en español según el Diccionario de la lengua española $(D R A E)^{3}$. Podemos encontrar el término rondalla como sinónimo de cuento y podemos hallar también el término cuentística como perteneciente o relativo al cuento. ¿Por qué se ha usado entonces el término en catalán? Porque es el que goza de mayor uso y tradición en la cultura catalana y en las escuelas valencianas. A la generalización del término ha contribuido en el País Valencià el trabajo de recopilación de las rondallas de Enric Valor $(1987)^{4}$, que tuvo y tiene una gran aceptación en las escuelas, y más recientemente el RonCat (Cercador de la rondalla catalana $)^{5}$. Este último es un proyecto creado por Carme Oriol y Josep Maria Pujol. El RonCat es una base de datos en red del proyecto de catalogación de las rondallas catalanas, financiado por la Universitat Rovira $i$ Virgili (URV) y por el Centre de Promoció de la Cultura Popular $i$ Tradicional Catalana (CPCPTC) de la Generalitat de Catalunya entre los años 2000-2002 y 2005-2007. Un instrumento que nos ha resultado fundamental para ampliar el canon y mostrar otros modelos como veremos más adelante.

\section{OBJETIVOS DE LA INVESTIGACIÓN}

Como formadora de maestros del Grado de Eduación Infantil y Primaria así como miembro del grupo de investigación GIEL (Grup d'Investigació en Ensenyament de Llengües), cuyas indagaciones giran en torno al aula y a la promoción de actividades de lectura y escritura con sentido, nos surgieron las siguientes preguntas:

1. ¿Por qué en el siglo XXI, en la época de lo audiovisual y digital, ponemos la mirada en la rondallística? Una palabra que, cabe añadir, suena a cuento tradicional en el bagaje cultural catalán, y no a

2 Este artículo es una reelaboración de la ponencia llevada a cabo en el marco de la Jornada del Máster «Literaturas hispánicas (catalana, gallega y vasca) en el contexto europeo» expuesta el 2 de julio de 2014 en la UNED.

$3 \mathrm{http} / / /$ lema.rae.es/drae/?val=afiliar [Acceso 22/02/2015].

${ }^{4}$ La edición de 1987 se trata de la versión original íntegra.

5 http://www.sre.urv.cat/rondcat/ [Acceso 22/02/2015]. 
cuento de creación actual, ya que para este último se suele usar la palabra cuento.

2. ¿Cómo y dónde encontramos los otros modelos anunciados en el título del artículo?

Este trabajo constituye una aproximación inicial a estas dos cuestiones. Nuestro objetivo consiste en conocer cuáles son las obras literarias que se leen en los primeros niveles escolares, en reivindicar la rondallística para la escuela y ofrecer otro canon con protagonistas activas y resolutivas como veremos a lo largo de estas páginas.

\section{LEER LOS CLÁSICOS}

La primera cuestión, de las dos planteadas en el apartado anterior, puede ser contestada rápidamente. En tanto que desempeñamos nuestra función docente en el Grado de Magisterio y la línea de investigación que tenemos entre manos consiste en enseñar a escribir a los niños pequeños (de entre 5 y 7 años) a partir del discurso literario, optamos, simple y llanamente por los clásicos. Para explicar por qué podríamos remitir al título de este apartado y formular la famosa pregunta Por qué leer los clásicos (Calvino 1992) y podríamos recordar su también famosa respuesta:

la única razón que se puede aducir es que leer los clásicos es mejor que no leer los clásicos. Y si alguien objeta que no vale la pena tanto esfuerzo, citaré a Cioran (que no es un clásico, al menos de momento, sino un pensador contemporáneo que sólo ahora se empieza a traducir en Italia): Mientras le preparaban la cicuta, Sócrates aprendía un aria para flauta. «¿De qué te va a servir?», le preguntaron. «Para saberla antes de morir» (Calvino 1992: 20).

Además y respecto a las rondallas, como explica Valriu (1998), desde hace siglos, la humanidad ha usado la literatura tradicional en general y las rondallas en particular para inserir a los miembros más jóvenes de la comunidad en su contexto social y cultural. Se han convertido en un vehículo de transmisión de pensamientos, de ideas y de acciones. El valor lúdico y estético de estas historias es innegable así como la transmisión de una percepción del mundo, de unos modelos de conducta, de una enseñanza intrínseca que abre un repertorio de propuestas e invita al juego simbólico, a la interpretación, a imitar al héroe, a establecer paralelismos y a reflexionar. Además, hay que añadir un elemento más que favorece su uso: la estructura de la narración y el lenguaje resultan fáciles de retener.

No pretendemos, con nuestra opción por leer los clásicos, abrir ninguna brecha entre la literatura tradicional y la actual. Y menos cuando se destaca la variedad y la cantidad de publicaciones de literatura infantil y juvenil en catalán en el País Valencià desde los años ochenta del pasado siglo hasta la actualidad. Una literatura que entró en las escuelas con la aprobación de la Llei d'Ús i Ensenyament del Valencià (LUEV 1983). Es decir, que mientras en otras naciones europeas la literatura para la infancia fue introducida a partir del siglo XVIII, en el País Valencià tiene un recorrido mucho más corto, de apenas 31 años (Fluixà 2011), 
aunque es cierto que se pueden encontrar algunos precedentes en los años veinte del pasado siglo. Sin embargo, en este periodo de tiempo, es decir, en estos últimos 31 años, se han publicado muchos títulos y muy diversos: podemos hacer referencia de nuevo a Josep Antoni Fluixà (2011), quien ofrece un panorama exhaustivo de autores, títulos, géneros, editoriales, etc. para concluir que la literatura infantil i juvenil valenciana ha aconseguit un nivell de qualitat equiparable a la de qualsevol altra literatura del nostre entorn en una llengua amb condicions socials més favorables que la nostra (Fluixà 2011: 29). Y añade:

Els nostres escriptors $i$ escriptores han superat la narració tradicional de tipus exclusivament folklòric $i$ han diversificat molt els temes $i$ els estils. Ens hi trobem obres de caràcter fantàstic o realista, trames de ciència-ficció o de descripció psicològica $i$ social, etc. Obres, en definitiva, instal-lades en la modernitat $i$ en evolució contínua per a reflectir el pas del temps i que, per sort, s'escriuen en un estil cada vegada més acurat $i$ sense abandonar l'objectiu bàsic de qualsevol obra literària: atraure l'interés del lector i estimular la seua capacitat de contemplació $i$ de creativitat estètica (Fluixà 2011: 29-30).

Ya hemos señalado antes que rehuimos esta dicotomía entre la literatura tradicional y la actual. Pero hay unas palabras de la cita anterior que nos llaman la atención: Els nostres escriptors i escriptores han superat la narració tradicional de tipus exclusivament folklòric $i$ han diversificat molt els temes $i$ els estils. Esta última frase (junto con esta otra destacada anteriormente del artículo citado de Fluixà (2011: 29): la LIJ valenciana ha aconseguit un nivell de qualitat equiparable a la de qualsevol altra literatura del nostre entorn en una llengua amb condicions socials més favorables que la nostra), nos induce a reflexionar alrededor de algunas ideas que podemos concretar en tres preguntas:

1. ¿Cuál es la literatura que se usa en la escuela? ¿Cuál es el canon escolar?

2. ¿Se trata de literatura tradicional?

3. ¿Suscita algún interés que esa literatura esté protagonizada por personajes femeninos?

Cabría comenzar por reflexionar sobre el canon. Son muchos los debates que se han producido alrededor de la lista de obras que se deben leer, sobre todo desde la publicación de El canon occidental de Bloom (1995). Bolaño (2011) resume las controversias suscitadas por dicha publicación sobre lo que se considera la lista de lecturas imprescindibles. El ámbito que nos ocupa es el escolar, por lo tanto, tenemos que mencionar a Mendoza (2009) en tanto que establece una serie de diferencias entre diversos tipos de canon (de aula, escolar, filológico y formativo). Nos interesa remarcar la relación entre el canon y los criterios didácticos. Dicha relación ya ha sido estudiada por este autor. Así, el profesor Mendoza afirma que en el ámbito educativo intervienen fundamentalmente dos factores para establecer el canon escolar: por una parte se han de tener en cuenta las orientaciones oficiales recogidas en los libros de texto y, por otra, las valoraciones y las concepciones de los docentes de acuerdo con las 
características del Proyecto Curricular de Centro y Área (Mendoza 2009:7). Añade que estas dos fuentes pueden o no coincidir, pero lo fundamental es que ayuden al «logro de una inicial y básica competencia literaria» (id.).

Las preguntas que acabamos de formular, que no podrán ser abordadas en su totalidad por las limitaciones de espacio del artículo, nos llevan a antiguos debates (muy fructíferos en la década de los noventa del pasado siglo) que giran alrededor de:

d) la conocida y debatida instrumentalización de la literatura,

e) la adecuación de las rondallas a la infancia,

f) las adaptaciones de las rondallas para la infancia,

g) la crítica feminista o los estudios de género.

\section{EL CONTEXTO DE LA INVESTIGACIÓN}

Como acabamos de señalar, no pretendemos dar cuenta de todos estos debates. Pero su permanencia en el tiempo y su complejidad es lo que propicia una investigación de carácter cualitativo, insistimos llevada a cabo en la escuela, en un colegio público situado en los alrededores de la ciudad de València, concretamente en la comarca de l'Horta Sud, que pretende promover la escritura. El estudio se desarrolla en los primeros niveles educativos (es decir, entre los 5 y 7 años), a partir de la renovación del canon literario en el marco de un proyecto que titulamos Les dones i els contes tradicionals, donde mostramos una serie de títulos desconocidos para el público en general, la comunidad educativa, los niños y las niñas, rescatados de la tradición rondallística catalana como luego veremos, para darlos a conocer en una exposición en la que los niños escriben los textos (fichas con referencias bibliográficas, con datos sobre las protagonistas y resúmenes de las rondallas) que se dan a conocer a todo el colegio así como a las familias al final del curso ${ }^{6}$.

Pero antes de llegar a la culminación de la exposición de cuentos, se mantienen durante todo el curso 2011-2012 reuniones periódicas, en forma de seminarios, con las maestras para discutir diferentes cuestiones. Entre ellas destacamos las tres más relevantes:

1. la adecuación de las rondallas para la infancia,

2. la adaptación de las rondallas para la infancia,

3. la presencia de los estereotipos femeninos en las rondallas.

${ }^{6}$ En la investigación ha participado todo el grupo docente de Educación Infantil y el primer ciclo de Educación Primaria. Es decir, 13 maestras y 170 niños y niñas de entre 5 y 7 años. 
Los instrumentos que nos han permitido obtener los datos para el análisis de los encuentros con las maestras son el estudio de las representaciones de las docentes y la observación de grupo (FGI, focus group interview) que explicamos a continuación.

\section{LAS REPRESENTACIONES DE LAS MAESTRAS SOBRE LAS RONDALLAS Y LA OBSERVACIÓN DE GRUPO (FGI)}

Ya hemos señalado que nuestro ámbito de trabajo de investigación se incluye en la didáctica de la lengua y esta «es una disciplina de intervención: sus resultados han de conducir a mejorar el aprendizaje de la lengua y sus usos» (Camps 2001: 10). Uno de los elementos claves de esta intervención estriba en explorar la cultura docente. En este sentido, para conocer cuáles son las obras literarias tradicionales que configuran el canon escolar, iniciamos una investigación en esta escuela donde hemos podido constatar que los títulos seleccionados por la comunidad educativa están en función de las creencias, las motivaciones y los valores de dicho colectivo. Son las conocidas representaciones que desde hace décadas ocupan un lugar importante en los estudios de las ciencias humanas y sociales. Las representaciones son definidas por Jodelet como formes de coneixement socialment elaborades $i$ compartides, orientades a la pràctica $i$ que participen en la construcció d'una realitat comuna a un conjunt social (Jodelet 1994 por Cambra 2000: 163). Se refieren, por lo tanto, a una forma de pensamiento social orientado hacia la comunicación del entorno. Esta forma de pensamiento no se entiende como individual sino que se entiende en tanto que ese individuo forma parte de un grupo. Dicho grupo, en este caso el docente, toma decisiones en el aula que a veces no provienen de su formación sino de otras fuentes como sus vivencias personales o experiencias anteriores. Pues bien, en trabajos anteriores nos hemos interesado por conocer cuáles son las representaciones de las docentes sobre las rondallas que cuentan en la escuela así como también por saber si los cuentos tradicionales que cuentan están protagonizados por mujeres y qué opinión les merecen estos arquetipos (Santolària 2010, 2013). Hemos usado diferentes instrumentos para obtener los datos: la entrevista semiestructurada y la observación de grupo. Esta última, según McMillan + Schumacher (2005: 471), es una variación de la entrevista que se convierte en una estrategia para obtener una mejor comprensión de un problema o la valoración de un problema, acontecimiento o idea a partir de la entrevista a un grupo de personas.

Los resultados de las entrevistas realizadas a las maestras aparecen en el cuadro que sigue resumidos en tres grupos:

\section{CUAdRo 1. LAS REPRESENTACIONES DE LAS MAESTRAS}

Grupo 1)

Las que asumen los postulados sociológicos de Cerda (1978: 10-11) y que consideran que los cuentos perpetúan desigualdades sociales además de ser machistas. Y por tanto, no los usan. 


\begin{tabular}{l} 
Grupo 2) \\
Otras, seguidoras de corrientes realistas, afirman que los cuentos tradicionales no son \\
aptos para la infancia porque pueden provocar trastornos psicológicos en los niños ya \\
que hablan de la muerte, o manifiestan relaciones violentas. En definitiva, muestran los \\
«antivalores» según algunas maestras. Y por tanto, tampoco los usan. \\
\hline $\begin{array}{l}\text { Grupo 3) } \\
\text { Un tercer grupo, seguidor de las ideas de Casanueva (2003), explica que desde el punto } \\
\text { de vista de la educación, la psicología y la estética el relato folklórico se puede asociar } \\
\text { sin ninguna dificultad a la infancia. Y estas maestras, sí los usan. }\end{array}$
\end{tabular}

Es decir, aquel debate sobre cuentos tradicionales e infancia que García Padrino califica en el año 2004 de «permanente o interminable» (2004: 29) sigue, en el contexto estudiado, diez años después, abierto e igual de permanente y de interminable. Cabe ahora preguntarse, aunque lo hemos apuntado al inicio, cuál es el rumbo que toma la investigación. Pero antes veamos cuáles son las obras que configuran el canon escolar de literatura tradicional que usan las maestras que apuestan por la narrativa tradicional.

\section{LAS RONDALLAS USADAS EN LA ESCUELA}

Las narraciones tradicionales que cuentan las maestras son La Ventafocs $o$ Cenicienta, La Caputxeta Vermella, La caseta de xocolate, La rateta que agranava l'escaleta, L'aneguet lleig, Els tres porquets i el llop, Rínxols d'or, La Blancaneu, El mig pollastre, El gegant del pi, La Picaternera, El pájaro, el espino y el abeto, La gallina de los huevos de oro y El gigante egoísta. Cabe añadir que la mayoría proviene de la tradición europea (de las recopilaciones de Perrault y de los hermanos Grimm), aunque se puede observar el uso de algunas rondallas recopiladas por Enric Valor. Hay que señalar que los cuentos de Perrault y de los hermanos Grimm se usan en ediciones y versiones de la factoría Disney. Adaptaciones que manifiestan algunas particularidades según los estudios de Lluch (2000: 42) por contener las siguientes características:

1. una fluidez narrativa basada en una serie de anécdotas cómicas,

2. imágenes dulces,

3. la substitución de escenas consideradas fuertes respecto del original,

4. la utilización de motivos musicales,

5. el protagonismo de los personajes secundarios,

6. la utilización de la tecnología.

Además, según apunta Lluch (2000: 44), estas versiones suponen un proceso de empobrecimiento de las precedentes a pesar del éxito social del que gozan gracias a elementos añadidos como las películas, objetos de consumo así como parques temáticos. 


\section{LOS PERSONAJES FEMENINOS DE LA LITERATURA TRADICIONAL}

Así las cosas, en primer lugar se realiza un seminario con el personal docente en el que reivindicamos el uso de la narración tradicional de tipo folclórico en la escuela. Pretendemos asimismo ahondar en el folclore, o en las versiones folclóricas próximas a nuestra área geográfica. En segundo lugar, se lleva a cabo otro seminario en el que se comparan las protagonistas de las versiones Disney con las que afloran en la literatura de nuestra área territorial, cosa que suscita un gran debate entre las maestras sobre si son o no sexistas. Y por último, se imparte otro seminario para hablar de las adaptaciones que resultarán imprescindibles para usar los cuentos en la escuela, como luego consideraremos.

Observemos ahora los personajes femeninos de las narraciones tradicionales. Es posible remitir al concepto de arquetipo de C. Jung para clasificar los diferentes tipos o patrones de mujer que aparecen en los cuentos tradicionales: estas figuras «no son más que representaciones conscientes (...) con frecuencia revelan su presencia sólo por medio de imágenes simbólicas (...); y se producen en cualquier tiempo o en cualquier parte del mundo. No tienen origen conocido» (Jung 1966: 68-69).

C. Jung establece un grupo de arquetipos básicos para facilitar el análisis psicológico de las actuaciones de los seres humanos (el arquetipo materno, la persona, el maná, el niño, el héroe, la doncella, el hombre sabio, etc.). La revisión de las diferentes figuras de modelos femeninos puebla el imaginario colectivo y dichos modelos aparecen en los cuentos tradicionales representados como la esposa abnegada, la mujer maternal y bondadosa, o la doncella inocente, cándida y pura, que dicho sea de paso, han sido los más divulgados. Aparecen las mujeres ignorantes y viciosas, producto de la tradición misógina. Conocidas también son las bondadosas (La Bella i la Bèstia, Abella), las cándidas y las que esperan al príncipe (Blancaneu), las virtuosas (La princesa que no sabía hilar, Les animetes, La Cendrosa, La mestra i el manyà). Contrariamente, no siempre es fácil encontrar en la literatura tradicional protagonistas femeninas con vidas paradigmáticas y llenas de sabiduría. Mujeres que, como Sherezade, salvan su vida y la de los demás gracias al ingenio, a la inteligencia y a la pericia, atributos que la narración antigua ha reservado generalmente al héroe masculino. Aún así, dentro de la tradición literaria, podemos descubrir personajes femeninos que responden también a este perfil com revelaremos más adelante.

Veamos algunos ejemplos. En primer lugar nos detendremos en los más leídos en la escuela (vide apartado 5) que además coinciden con los que gozan de mayor presencia social tanto en versiones cinematográficas como libros, cómics o imágenes u objetos de consumo: Cenicienta, la Bella durmiente del bosque y Blancanieves. Nos fijaremos en lo que hacen y en cómo son, pero antes hay que decir que hemos optado por ofrecer versiones clásicas. Nos referimos a las versiones recogidas por los hermanos Grimm y Perrault traducidas al catalán por Carles Riba. A la hora de observar estos personajes hemos atendido a las características físicas, las psicológicas y los comportamientos que presentan las protagonistas de las narraciones elegidas. Podemos leer los ítems que nos han permitido el análisis en el cuadro siguiente: 
Cuadro 2. Descripción de las PROtagonistas (BASAdo en Oliveres 2007: 62-64)

\begin{tabular}{|l|l|}
\hline $\begin{array}{l}\text { ¿Cómo aparece descrita } \\
\text { psicológicamente? }\end{array}$ & ¿Qué acciones realiza? \\
\hline $\begin{array}{l}\text { ¿Es dulce, servicial, malvada, } \\
\text { cotilla, gandula, fina, trabajadora, } \\
\text { atrevida, valiente, lista...? }\end{array}$ & $\begin{array}{l}\text { ¿Cuida la casa? ¿Se cuida a sí misma? ¿Hace } \\
\text { cosas fuera de casa? ¿Trabaja fuera de casa? } \\
\text { ¿Realiza acciones destinadas a seducir a los } \\
\text { demás? ¿Realiza acciones destinadas a provocar } \\
\text { «el mal» en otras personas? ¿Realiza acciones } \\
\text { destinadas a provocar «el bien» en otras } \\
\text { personas? ¿Toma decisiones? ¿De qué tipo? }\end{array}$ \\
\hline
\end{tabular}

\subsection{Caracterización de la Cendrosa o Cenicienta}

(...) Allí (a la cuina) havia de fer feinasses del matí al vespre, llevar-se abans d'ésser de dia, portar aigua, encendre foc, cuinar i passar bugada. (...) Al vespre, cruixia de tant de treballar, no anava al llit, sinó que havia d'ajaçarse vora la llar, a les cendres. I com que per això sempre anava polsosa i bruta, li van traure el motiu de Cendrosa (Grimm, traducido por Riba, 1935: 28).

\subsection{Caracterización de la Bella dorment del bosc o la Bella durmiente del bosque}

(...) Aquesta pobra dona no havia tingut notícia que el rei havia prohibit de filar amb el fus.

- Què feu, aquí, bona dona? -li va preguntar la princesa.

- Ja ho veus estic filant_li va respondre la vella, que no la coneixia.

- Oh, que és bonic! -

Va prosseguir la princesa-I I com es fa? Deixeu-m'ho fer a mi, a veure si en sé.

Però així que va agafar el fus, com que era molt decidida i una mica esverada $i$ tot, i com que, d'altra banda, les fades ho havien disposat així, se'l va clavar a la mà $i$ va caure sense sentits (Perrault 1983: 97)

\subsection{Caracterización de la Blancaneu o Blancanieves}

(...)

- Si vols cuidar-te de casa nostra, cuinar, fer els llits, rentar, cosir i fer mitja, $i$ tenir-ho tot endreçat $i$ net, et quedaràs amb nosaltres $i$ no et mancarà de res.

- Sí-digué Blancaneu - de tot cor.

I es va quedar amb ells.

Els endreçava tota la casa. Al matí se n'anaven a la muntanya i cercaven coure $i$ or; al vespre tornaven, $i$ havien de tenir el menjar a punt (Grimm, traduiit per Riba, 1935: 12). 
De todos son bien conocidas estas tres narraciones. ¿Qué hacen estos personajes? La idea que transmiten los textos es clara: Cenicienta y Blancanieves limpian, se ocupan de la casa y carecen de iniciativa. La Bella durmiente espera a su príncipe azul y es castigada por desobedecer. Este es el prototipo de mujer que se enseña: sumisa, pasiva y hermosa.

Al debate sobre el uso social y educativo de las rondallas hay que sumar otro que desde hace décadas, y sobre todo en los años noventa del pasado siglo en el Estado Español, ha sido bastante fructuoso: el análisis que de las rondallas ha elaborado la crítica feminista o más recientemente los estudios de Literatura Infantil y Juvenil (LIJ) y desigualdad de género. Este segundo y más reciente marco general, la Didáctica de la LIJ, se reivindica como un espacio importante para trabajar y transformar las desigualdades de género ya que se hace necesario, como parte de la definición de una nueva identidad de género en el siglo XXI, la didáctica de la LIJ como instrumento de indagación cultural y como elemento relevante en la formación de identidades, así como abordar la historia de la LIJ desde una perspectiva crítica, interdisciplinar e intercultural que además se refleje en el currículum (Aguilar 2006).

Somos conscientes del debate que ha existido y que perdura, aunque en menor medida en la actualidad, alrededor de los personajes femeninos de los cuentos tradicionales especialmente en el mundo educativo. Hay ya una larga tradición de estudios sobre el tema que arranca en la segunda guerra mundial: «Después de la guerra los cuentos se consideraron retrógrados desde la progresía y aparecen dos tendencias: la transfiguración de los cuentos clásicos invirtiendo la tradición y la fusión de nuevos elementos y temas tradicionales» (Aguilar 2006: 9). Esta investigadora resume los estudios realizados desde la década de los setenta del siglo XX al tiempo que destaca los primeros análisis elaborados por la Universidad de Princeton donde se investigó la imagen de la mujer en la literatura infantil en quince colecciones de libros para concluir «que lo que aprendía la infancia era que los hombres eran dominadores y las mujeres pasivas» (Aguilar 2006:10).

\section{LA PROPUESTA DE OTRAS HEROÍNAS}

Recordemos que uno de los objetivos de este artículo estriba en ofrecer rondallas que muestren heroínas con rasgos inteligentes. Vamos a proponer otros tres personajes: Rosella, la Dent d'Or y Blancaflor que como veremos no solo limpian, también piensan y actúan. La Dent d'or y Blancaflor son las protagonistas de los cuentos que llevan sus nombres. El caso de Rosella es distinto: es la protagonista de la rondalla El castell d'iràs $i$ no en tornaràs. Las tres narraciones son recogidas por Joan Amades (1982). Antes de presentar ejemplos de los tres cuentos que exhiben los rasgos activos de las protagonistas que nos interesa remarcar, hay que señalar que se trata de narraciones desconocidas para el público en general y que no resulta fácil encontrar, como hemos señalado anteriormente, cuentos que contengan este tipo de personajes (vide apartado 6). ¿Cómo y dónde se han encontrado? 


\subsection{Las otras protagonistas}

Hemos indagado en la base de datos del RonCat citada al principio de nuestro artículo. Dicha base de datos permite consultar información bibliográfica así como el contenido de las rondallas recogidas en lengua catalana en toda esta área lingüística. El RonCat representa un paso más allá, un paso digital, en el mundo de la catalogación de las rondallas. Un mundo que arranca en la década de los treinta del pasado siglo. Hacia 1931-1932 apareció la obra de Johanes Bolte y Georg Politva, Anmerkungen zu den Kinde- und Hausmärchen der Brüder Grimm, que consistía en un conjunto de notas comparativas sobre los cuentos publicados por los hermanos Grimm. Esta obra abrió el camino a la llamada escuela finlandesa, creadora del método de investigación folclórica denominado histórico-geográfico, que ha aportado los índices de tipos y motivos de Aarne y Thompson. Según Rafael Beltrán y Marta Haro, el clásico Types of Folktale (1910) fue revisado por Thompson dos veces, en 1928 y en 1961, quien lo amplió. Esta última clasificación fue actualizada por Hans-Jörg Uther, The Types of International Folktales. A Classification and Bibliografy. Based on the System of Antti Aarne and Stith Thompson (2004), «que representa una base de partida, un diccionario vivo y abierto que acepta aportaciones que vienen periódicamente de la cuentística que pervive en todo el mundo» (Bertran + Haro 2006: 14). Estos estudiosos añaden que permite la comparación con recopilaciones de otras partes y así se convierte en un instrumento imprescindible de investigación. En el Estado Español, también contamos con los trabajos de Julio Camarena y Máxime Chevalier (1995) quienes elaboraron el Catálogo tipológico del cuento folclórico español que recoge también las tradiciones catalana, gallega y vasca. Hemos usado todos estos trabajos y clasificaciones para buscar los tipos folclóricos, es decir, los argumentos básicos que permanecen inalterables en la tradición y que son comunes a las narraciones de diferentes geografías (Hernández Fernández 2006). Aunque el buscador de Carme Oriol y Josep Maria Pujol, el RonCat, es el que nos ha permitido encontrar estas otras heroínas como hemos visto anteriormente. Este buscador también nos permite leer los motivos y argumentos de las rondallas? Veamos los tres ejemplos seleccionados ahora:

\footnotetext{
7 Se pueden ver los trabajos de Propp $(1984,1985)$ y Thompson (1977) para entender los tipos y motivos. El motivo 313 (la fugida màgica) es compartido por Rosella y Blancaflor mientras que el 884 (donzell, donzella) corresponde a la Dent d'or. A continuación ofrecemos los resúmenes ofrecidos en el RondCat. En cuanto al 313 es el siguiente: L'heroi arriba a una casa. L'amo (un gegant o el Diable) li encarrega tasques impossibles i ell les du a terme gràcies a l'ajut de la filla de l'amo. La noia fa una coqueta màgica que pot respondre les preguntes dels seus pares quan ella no hi sigui i fuig amb l'heroi. Durant la nit els pares de la noia fan preguntes a la seva filla per veure si hi és. La coqueta respon per ella. Es fa de dia i els pares descobreixen que la filla ha fugit, surten a buscar-la i la noia evita diverses vegades, mitjançant procediments màgics (obstacles, transformacions, etc.), que els capturin. En acostar-se a casa seva, l'heroi demana a la noia que s'esperi mentre ell va a avisar els seus pares. Ella li adverteix que no besi o es deixi tocar per ningú, però un cop hi arriba besa la seva mare o l'abraça algú $i$ oblida la noia. En veure que passa el temps, la noia va a buscar-lo i es lloga a casa seva de criada, es fa reconèixer (explicant la seva història, mitjançant una endevinalla, etc.) i es casen. http://www.sre.urv.cat/rondcat/cercar. php?lang=cat\&func=cercar [Acceso 22/02/2015]. A continuación podemos ofrecer el de La Dent
} 


\subsubsection{Caracterización de Rosella}

Se trata de un personaje que dirige las acciones del príncipe y que razona de forma diligente al tiempo que no es cuestionada por nadie:

Mentre jo preparo el llit i recullo les robes, les joies $i$ els diners, tu vés, baixa a la quadra a cercar el cavall més sec i més magre, que és el més corredor de tots. No n'agafis cap altre, perquè no corren tant. Quan tinguis el cavall, surt a fora al jardí i espera'm que jo vindré de seguida (Amades 1982: 598).

\subsubsection{Caracterización de la Dent d'or}

Esta heroína es capaz de negociar con el rey para conseguir su propósito: quedarse con el caballito que la ayudará posteriormente a escapar. Además consigue con su pericia engañar al príncipe:

(...) La Dent d'or, com si fos un home voltava pels carrers cridant:

- Qui vol llogar un criat? Qui vol llogar un criat?

Heus ací que van passar pel davant del palau del rei, el rei ho va sentir, i com que necessitava un criat perquè li espolsés la roba, el va llogar. En tractar tractes, ella va dir al rei:

- Ja veurà, senyor rei, tinc un cavallet i me l'estimo molt, perquè ja el tenia quan era petit. Jo no me'n voldria pas separar (Amades 1982: 557).

(...) La dent d'or es va proveir d'un guitarronet. Quan fou hora de despullar-se, la Dent d'or va dir que ell no podia pas dormir, sense tocar una estoneta un guitarronet, que tenia des de petit. I, sense treure's ni un fil de roba, es va seure al llit $i$ toca que toca. Amb aquell «rinc, gatarric, crinc, crinc», el príncep es va adormir com un soc. Ella, però, va vetllar tota la nit, perquè si el príncep es despertava no l'atrapés. Molt abans de l'hora de llevar-se, la Dent d'or es posà la jupa i, quan el príncep es va despertar, la va trobar vestida del tot com si tal cosa (Amades 1982: 528).

\subsubsection{Caracterización de Blancaflor}

Nuestra protagonista resuelve los problemas que el príncipe le plantea, además es capaz de desafiar a todo un auditorio para convencer al héroe y a su pueblo de que ha optado por el camino equivocado:

El príncep li explicà el que li passava, la donzella prometé treure'l de tots els perills i resoldre-li tot el que el seu pare li manaria. Li digué que així que ella fos fora, s'acluqués els ulls (...). Li digué que de seguida que es trobés en un conflicte la cridés, encara que només fos mentalment, pel seu nom, que era Blancaflor, i que ella sortiria i el trauria de tot (Amades 1982: 27).

\footnotetext{
d'or: L'herö̈na se'n va de casa (fuig del dimoni amb qui s'ha casat sense saber-ho, substitueix el seu pare per anar a la guerra, etc.). Es fa passar per home i el rei la lloga de criat (o bé fa de soldat). El fill del rei sospita que no és un home i la posa a prova diverses vegades fins que, finalment, aconsegueix que l'herö̈na reveli involuntàriament la seva identitat i es casa amb ella. http://www. sre.urv.cat/rondcat/ajuda_tipus.php?lang=cat\&id_tipus=0884 [Acceso 22/02/2015].
} 
(...) Preguntà que si un home tenia una espasa molt bona, que li feia guanyar totes les bregues, $i$ el treia de tots els perills, $i$ moltes vegades li havia salvat la vida, $i$ venia un moment en què la perdia $i$, com que sense espasa no es pot anar pel món, en cercava una l'altra, però que si quan ja tenia la nova, la sort li feia tornar a trobar la vella, ¿amb quina de les dues espases s'havia de quedar aleshores? (Amades, 1982: 31).

En resumen, como vemos, estas otras heroínas de los cuentos tradicionales piensan, se enfrentan a otros sujetos con su ingenio y resuelven situaciones conflictivas. Estos comportamientos y actitudes muestran personajes de cuento que nos alejan de las mujeres pasivas que aparecían en los estudios a los que aludíamos en el apartado 6.

\section{ADAPTAR LOS CLÁSICOS}

Ahora bien, aunque ya disponemos de otras heroínas más activas y resolutivas se nos vuelve a presentar otro problema: las rondallas de Amades (1982) que hemos usado no son aptas para la infancia por varias razones: en primer lugar, porque la edición que hemos visto es larga, presenta un estilo, una sintaxis y un léxico complejo para nuestros destinatarios, además no posee ilustraciones. Por estos motivos no presentamos esta edición directamente a los niños (recordemos que tienen entre 5 y 7 años), son las maestras quienes han de narrar oralmente los cuentos. En segundo lugar, porque las rondallas manifiestan, según la opinión de algunas docentes, complicaciones temáticas: el tratamiento de la muerte, la crueldad, la venganza, la violencia, etc., y referentes culturales, sobre todo religiosos, desconocidos para la mayoría de los niños, como por ejemplo, el personaje del demonio.

Por lo tanto, ajustar los cuentos elegidos al público infantil representa uno de los mayores retos de todo el proyecto. Nuestro propósito continuaba firme en el seminario que dedicamos a tal efecto: mantener el espíritu del cuento de la forma más fiel posible, huyendo de adaptaciones ternuristas (Teixidor 1995:14), excesivamente protectoras con la infancia y habitualmente alejadas de la literatura de calidad y del placer estético. Tenemos en cuenta a la hora de adaptar las narraciones los estudios precedentes sobre las posibles formas de modificar los cuentos, como por ejemplo las aportaciones de Teresa Colomer (2000: 70-71) a partir de Ruth McDonald (1982, «The tale re-told: feminist fairy tales» Childen's literatura assoctiation quarterly $7,18-20$ ) quien, recordemos, platea tres maneras de cambio, a saber:

1. Se puede presentar los cuentos sin alteraciones y tratar posteriormente las posibles consecuencias perjudiciales.

2. Se puede reescribir los cuentos cambiando los aspectos ideológicamente inaceptables. A esta opción se adscribe la literatura infantil antiautoritaria y la literatura políticamente correcta.

3. Se puede utilizar los motivos folclóricos en la producción de otros cuentos para conseguir lecturas menos convencionales. 
Iniciamos así el tercer seminario con el grupo de maestras con una serie de consideraciones al respecto en las que se tenía en cuenta:

1. Respetar las versiones originales al máximo aún a sabiendas de que contar es recontar. A sabiendas de que debemos considerar el texto conservado de una rondalla como una partitura provisional (Lluch + Salvador, 2000: 44). Aunque nuestra opción estriba en presentar los cuentos sin alteraciones (como explica Teresa Colomer (2000: 70-71), pero descartando que mantener los motivos y temas de las rondallas pueda ocasionar ningún tipo de consecuencias perjudiciales. Lo hemos podido comprobar en el aula, con la escritura de los niños.

2. Observar los personajes femeninos atendiendo a los ítems que hemos observado en el apartado 6.

3. Tener en cuenta las propuestas de Genette (1982) para adaptar los clásicos.

4. Considerar los elementos narrativos (Propp, 1985; Greimas, 1971, 1983; Courtés, 1997).

5. Valorar los elementos lingüísticos como las fórmulas iniciales y finales de los cuentos, las estructuras propias de la narración, las descripciones de los personajes, etc.

\section{LA ESCRITURA DE LOS NIÑOS Y NIÑAS}

En el apartado 3 hemos señalado que los alumnos del último curso de Educación Infantil y del primero y segundo de Educación Primaria debían escribir los textos con notas bibliográficas y resúmenes de los cuentos para realizar una exposición escolar. A continuación ofrecemos un ejemplo de un alumno de segundo de Educación Primaria que recoge el trabajo realizado en el aula. Podemos observar que usa explícitamente tres adjetivos para caracterizar a la protagonista (Valenta, amigable, llesta) así como resalta las acciones que realiza la heroína (Cavalcava, se disfressava i tocava la guitarra). Es decir, la heroína ofrece una imagen inteligente y activa que el niño recoge en su escrito. Veamos el ejemplo ${ }^{8}$ :

8 Ofrecemos una traducción al castellano del texto original escrito por este alumno para facilitar la lectura en tanto que, al tratarse de los primeros niveles escolares, la ortografía no está consolidada y este hecho puede dificultar la comprensión del texto a un lector no habituado a leer escritos de los niveles iniciales. El texto es el siguiente:

Título: La Dent d'or.

Autor/autora: Joan Amades.

Editorial: Adaptación.

Nombre de los personajes: La Dent d'or, el caballito, el demonio, el alma del abuelo y el príncipe.

¿Cómo es la protagonista del cuento?: La Dent d'or es: valiente, amigable, lista.

¿Qué hace la protagonista del cuento?: Cabalgaba, se disfrazaba y tocaba la guitarra. 
Títol: «La dent D’or»

Autor/autora: Joan Amades

Editorial: Adaptació

Nom dels personatges: La dent D’or, el cavallet, el dimoni, La nimeta del seu llallo i el princep.

Com és la protagonista del conte?: La dent D'or es: valenta, amigable, llesta. Què fa la protagonista del conte?: Cavalcava, se disfressava i tocava la guitarra.

\section{Resum:}

Hi havia una vegada una xica que samare savia mort $i$ li va dir que es cassara amb un xic que tinguera una dent d'or si no tindria mala sort. Primer el dimoni es volia casarse amb ella pero el cavallet li va rescatar. Despres el princep també volia casarse amb ella pero el cavall la va ajudar i el cavall li va donar una pota amb la ferradura d'or al princep i seli va ficar el clau. Al final es varen cassar $i$ varen ser feliços.

(Arnau, 31/05/2012)

\section{CONCLUSIÓN}

A lo largo de este artículo hemos trazado un camino sobre algunos temas que tienen que ver con la rondallística y la escritura infantil, con la elección de las obras literarias así como con los mensajes que aparecen. También hemos reivindicado la literatura tradicional, hemos aportado algunos trazos sobre un estudio de campo que cuenta con el personal docente y hemos presentado tres protagonistas clásicas que actúan y resuelven en contraposición a otras más pasivas.

En definitiva, acabamos respondiendo a las dos preguntas de investigación que planteábamos al inicio de estas páginas. En el siglo XXI, en la época de lo digital, el uso educativo de la rondalla se asocia sin duda a la rondalla misma, como defiende Pisanty (1995:9) «los cuentos son un género narrativo hecho a propósito para ser usado, o sea, sometido a los fines específicos del usuario y adaptado a las situaciones particulares en que se encuentra en cada ocasión». Precisamente, como sostienen Lluch + Salvador (2000: 46) «porque pertenece a nuestro patrimonio cultural colectivo y porque cada miembro de nuestra cultura mantiene un vínculo duradero, profundo y personal con él». Además este vínculo apela a lo conocido, a lo emotivo, a lo ejemplificador, a la moralidad tamizada por el ejemplo de lo que ocurrió a otros.

Por lo tanto, y a tenor de lo que escriben los niños y niñas, como hemos visto en el apartado anterior, reivindicamos la rondalla como género literario en la escuela tanto para el disfrute como discurso motivador de la escritura, así como

Resumen: Había una vez una chica que su madre se había muerto y le dijo que se casara con un chico que tuviera un diente de oro si no tendría mala suerte. Primero el demonio se quería casar con ella pero el caballito la rescató. Después el príncipe también quería casarse con ella pero el caballito la ayudó y el caballito le dio una patada con la herradura de oro al príncipe y se le puso el clavo. Al final se casaron y fueron felices. 
fuente de riqueza literaria y de sabiduría en la que podemos encontrar personajes con diferentes rasgos como los que hemos mostrado. Modelos que se desmarcan de los roles tradicionales y que pueden contribuir a ampliar la imagen que tienen los niños de los personajes femeninos de los cuentos. De hecho, estas rondallas pueden ayudar a cambiar la idea de los niños y de las niñas respecto de algunos modelos femeninos de los cuentos tradicionales, ya que como hemos podido ver, es posible afirmar que no toda la literatura tradicional muestra personajes femeninos sumisos y pasivos. Así, se puede colaborar, gracias también a la educación literaria, a fomentar otros modelos de actuación porque:

las historias que contamos a los niños, las narrativas que les damos para bastir un sentido de experiencia cultural, constituyen una especie de cartografia metafórica, mapas de significado que les permiten conferir un sentido al mundo. De hecho, son una contribución al sentido de identidad de los niños, una identidad que es a la vez personal y social: diríamos que los relatos marcan la manera como los niños encuentran un hogar en el mundo (Watkins, 1992, por Lluch + Salvador 2000: 51).

Por último, podemos afirmar que interrelacionar la literatura con la enseñanza de la lengua representa un elemento motivador en el campo de la didáctica de esta disciplina, aspecto que nos permite sumarnos a la corriente que defiende la interrelación de la didáctica de la lengua y de la literatura (Bronckart 2011). Al tiempo que recalcamos la necesidad de mostrar investigaciones y experiencias de aula que den cuenta de lo que pasa en este espacio y que recojan todas las voces de lo acontecido en las clases: las de los docentes y las del alumnado.

\section{BIBLIOGRAFÍA}

Aarne, A. + Thompson, S. (1961) The Types of the Folktale: Classification and Bibliography, Helsinki, Academia ScientiariumFennica. [Trad. F. Peñalosa. Los tipos del cuento folklórico. Una clasificación. Helsinki, Academia Scientiarium Fennica, 1995].

Aguilar, C. (2006) «Género y formación de identidades», CLIJ: Cuadernos de Literatura Infantil y Juvenil, 191, pp. 7-15.

Amades, J. (1982) «El castell d'iràs i no en tornaràs», Folklore de Catalunya. Volum I, Barcelona, Editorial Selecta, pp. 591-605.

- (1982) «La Blancaflor», Folklore de Catalunya. Volum I, Barcelona, Editorial Selecta, pp. 26-31.

- (1982) «La Dent d'or», Folklore de Catalunya. Volum I, Barcelona, Editorial Selecta, pp. 524-531.

Beltrán, R. + Haro, M. (eds.) (2006) El cuento folclórico en la literatura y en la tradición oral, València, Publicacions de la Universitat de València.

Bloom, H. (1995) El canon occidental. La escuela y los libros de todas las épocas, Barcelona, Anagrama. 
Bolaño, A. (2011) «Cómo leer y por qué El canon occidental de Harold Blomm», Amauta, 17, pp. 25-50.

Bolte, J. + Politva, G. (1913) Anmerkungen zu den Kinde- und Hausmärchen der BrüderGrimm. Leipzig, Dieterich'sche Verlangsbuchhandlung. [Versión digitalizada https://archive.org/details/anmerkungenzuden02grim. Acceso 22/06/2014].

Bronckart, J. P. (2011) «Le statut épistémologique de la didactique de la langue et de la littérature: entre les sciencies sociales et les humanités». La investigación en didáctica de la lengua y la literatura: situación actual y perspectivas de futuro, Madrid, Publicaciones de la SEDLL, pp. 31-57.

Calvino, I. (1992) Por qué leer los clásicos, Barcelona, Tusquets.

Camarena, J + Chevalier, M. (1995) Catálogo tipológico del cuento folklórico español. Cuentos maravillosos, Madrid, Gredos.

Cambra, M. (2000) «Introducció. El pensament del professor: formació per a la pràctica reflexiva». Camps, A. + Rios, I. + Cambra. M., (coords.) Recerca $i$ formació en didàctica de la llengua, Barcelona, Graó, pp. 161-171.

Camps, A. (coord.) (2001) El aula como espacio de investigación y reflexión. Investigaciones en didáctica de la lengua, Barcelona, Graó.

Casanueva, M. (2003) Relaciones entre el folklore y literatura infantil. Claves interpretativas, Salamanca, Ediciones Antema.

Cerda, H. (1978) Literatura infanil y clases sociales, Madrid, Akal.

Colomer, T. (2000) «La formació i renovació de l'imaginari cultural: l'exemple de la Caputxeta Vermella», en Lluch, G. (ed.). De la narrativa oral a la literatura per a infants, Alzira, Bromera, pp. 55-94.

Courtés, J. (1997) Análisis semiótico del discurso, Madrid, Gredos.

Hernández Fernández, Á. (2006) «Hacia una clasificación estructural y temática del cuento folklórico». Revista de literaturas populares, 1, pp. 153-176.

Fluixà, J. A. (2011) «Panorama de la literatura infantil i juvenil al País Valencià». L'aiguadolç 39, pp. 9-31.

García Padrino, J. (2004) «El canon en la literatura infantil o el debate interminable». Primeras noticias, Barcelona, 205, pp. 29-43, http://www.fundaciongsr.org/documentos/6956.pdf [Acceso 22/02/2015].

Genette, G. (1982) Palimpsestes. La litératture au second degré, Paris, Éditions du Seuil.

Greimas, A. J. (1971) Semántica estructural: la investigación metodológica, Madrid, Gredos.

- (1983) La semiótica del texto: ejercicios prácticos. Análisis de un cuento de Maupassant, Buenos Aires, Paidós. 
Grimm, Ll. J. + Grimm, G. C. (1935) Rondalles de Grimm, Traduïdes per Carles Riba, «Blancaneu», Barcelona, Editorial Joventut, pp. 9-17.

- (1935) Rondalles de Grimm, Traduïdes per Carles Riba, «La Cendrosa», Barcelona, Editorial Joventut, pp. 28-34.

Jung, C. (1966) El hombre y sus símbolos, Madrid, Aguilar.

Lluch, G. + Salvador, V. (2000) «La Cenicienta, un mito vigente». CLIJ: Cuadernos de Literatura Infantil y Juvenil, 130, pp. 44-54.

Lluch, G. (2000) «Dels narradors de contes a Walt Disney: un camí cap a l'homogeneïtzació», en Lluch, G. (ed.). De la narrativa oral a la literatura per a infants, Alzira, Bromera, pp. 17-53.

LUEV (Llei d'Ús i Ensenyament del valencià) LLei n. 4. DOGV Diari Oficial de la Generalitat Valenciana, València, 23 de noviembre de 1983.

McMillan, J. H. + Schumacher, S. (2005) Investigación educativa, Madrid, Pearson Addison Wesley.

Mendoza, A. (2009) Biblioteca Virtual Universal, Facilitado por Biblioteca Virtual Miguel de Cervantes «La renovación del canon escolar», http://www. biblioteca.org.ar/libros/134811.pdf [Acceso15/02/2015].

Oliveres, I. (2007) El tractament de la dona en el repertori de cançons de primària. Anàlisi dels textos $i$ de les il-lustracions de les cançons dels llibres de text des d'una perspectiva de gènere. http://www.xtec.cat/sgfp/ llicencies/200607/memories/1647m.pdf [Acceso 22.02.2015].

Perrault, C. (1983) Contes d'antany, «La bella dorment del bosc», Barcelona, Barcanova, pp. 95-107.

Pisanty, V. (1995) Cómo se lee un cuento popular, Barcelona, Paidós.

Propp, V. (1984) Las raíces históricas del cuento, Madrid, Editorial Fundamentos.

- (1985) Morfología del cuento, Madrid, Editorial Fundamentos.

Santolària, A. (2010) «Representacions de mestres d'Educació Infantil sobre els contes tradicionals. Un estudi introductori a partir dels arquetipus femenins» en García, M. et alii (eds). Interacció Comunicativa i Ensenyament de llengües, València, Publicacions de la Universitat de València, pp. 557-564.

- (2013) «Blancaflor, la Dent d'or i Rosella: tres herö̈nes en cerca d'un cànon escolar» en Lluch, G. et alii (eds.) El relat: Literatura, lectura i escriptura, Quaderns de Filologia. Estudis literaris, 18, pp. 171-189.

Teixidor, E. (1995) «Literatura juvenil: las reglas del juego», CLIJ: Cuadernos de Literatura Infantil y Juvenil, 72, pp. 8-15.

Thompson, S. (1977) The folktale. Berkeley, Los Angeles, London, University of california press. 
Valor, E. (1987) Rondalles valencianes, València, Edicions de la Federació d'Entitas Culturals del País Valencià.

Valriu, C. (1998) «Les rondalles i la literatura infantil», Articles de Didàctica de la Llengua i de la Literatura, 16, pp. 69-81. 
